\title{
Architectural Design Interventions for Sedentary Behaviour among Workers in Office Buildings in Enugu, Nigeria
}

\author{
Austine Ezezue $^{1, *}$, Eziyi Ibem ${ }^{2}$, Chinwuba Odum $^{2}$, Bons Obiadi $^{1}$ \\ ${ }^{1}$ Department of Architecture, Nnamdi Azikiwe University, Awka, Anambra State, Nigeria \\ ${ }^{2}$ Department of Architecture, University of Nigeria, Enugu Campus, Enugu State, Nigeria
}

Received November 1, 2020; Revised November 30, 2020; Accepted December 30, 2020

\section{Cite This Paper in the following Citation Styles}

(a): [1] Austine Ezezue, Eziyi Ibem, Chinwuba Odum, Bons Obiadi, "Architectural Design Interventions for Sedentary Behaviour among Workers in Office Buildings in Enugu, Nigeria," Civil Engineering and Architecture, Vol. 8, No. 6, pp. 1451 - 1462, 2020. DOI: 10.13189/cea.2020.080627.

(b): Austine Ezezue, Eziyi Ibem, Chinwuba Odum, Bons Obiadi (2020). Architectural Design Interventions for Sedentary Behaviour among Workers in Office Buildings in Enugu, Nigeria. Civil Engineering and Architecture, 8(6), 1451 - 1462. DOI: $10.13189 /$ cea.2020.080627.

Copyright $(2020$ by authors, all rights reserved. Authors agree that this article remains permanently open access under the terms of the Creative Commons Attribution License 4.0 International License

\begin{abstract}
Sedentary behaviour within buildings has become a major public health issue particularly now that a large number of people are engaged in one form of office work or the other. In the midst of this, there is a paucity of research on how the design of office spaces can help discourage sedentary behaviour and reduce the health risks associated with it among office workers, especially in the developing countries. This study investigated sedentary behaviour among office workers in Enugu, Nigeria, with a view to improving understanding of the architectural design strategies for checking it. The data were sourced from a survey of 106 office workers in the study area and analysed using descriptive statistics, ANOVA and Duncan multiple comparison test. The findings show that the predominant office layouts identified were personalized and co-working layouts with workers spending around $93 \%$ of the total time at work sitting. Variations were observed in the level of physical activity of workers in the different office layouts with those in personal office layouts manifesting sedentary behaviour more than those in co-working and open-plan office layouts. The findings are incisive in noting that to discourage sedentary behaviour in offices and reduce the exposure of workers to sedentary related health risks, architects and engineers should pay adequate attention to co-working and open plan office layouts, centralised and shared office resources and the use of lobbies and corridors in linking main office
\end{abstract}

spaces to ancillary facilities.

Keywords Architectural Design, Enugu, Office Workplace, Physical Activity, Sedentary Behaviour, Workers

\section{Introduction}

Before now, discussions on indoor environmental quality in office buildings had focused mainly on ventilation and comfort factors. However, the revelation by the European Commission [1] that a high majority of the global population spend around $90 \%$ of their time indoors which helped to redirect research attention to the interactions between the indoor environment and building users as well as the various physical, chemical, biological, and design factors that influence these. Of importance in current research efforts is the health risk associated with indoor environment and sedentary behaviour (SB) or lifestyle and how this can be minimised in today's workplace [2].

Sedentary behaviour (SB) or lifestyle such as sitting and lying has been described as the lack of physical activity or not being able to attain a certain level of activity [3]. Several authors have noted that physical 
activities, lifestyle, fitness, recreational, occupational and sports activities rather than exercise alone can bring a lot of health benefits $[4,5,6,7]$. In addition to diet, research has also shown that the nature of work can promote sedentary behaviour in the working population [8]. Some authors were of the view that sedentary behaviour can be associated with increase in overweight and obesity, with the associated health implications $[9,10]$. The Centre for Disease Control and Prevention [11] specifically noted that physical inactivity was a major public health issue in the United States of America as only one in every five adults in that country can be considered as meeting the recommended aerobic and muscle-strengthening guidelines. Moreover, sedentary behaviour has been linked to poor health and increasing mortality rate due to cardiovascular diseases and cancer [7,12,13]. In a developing country like Nigeria, the World Health Organization [7] and Guardian Newspaper [14] reports indicate that the burden of cardiovascular and other chronic diseases, which account for $24.2 \%$ and $25.1 \%$ of all mortalities in males and females, respectively, has been directly or indirectly linked to sedentary lifestyle. This has been attributed to a number of factors including the adoption of western life styles and culture, preference for white collar jobs, reduced physical activity and inappropriate dieting $[15,16]$. Research has shown that for many office workers, occupational sitting time contributes to at least half of their daily sitting time, with many sitting for more than three-quarter of their work day leading to sedentary behaviour $[17,18,19]$. As a result, it has been argued that today's workplace represents an ideal opportunity for new initiatives and interventions that can reduce work-related sedentary behaviour and promote physical activity at work [8]. Dugdill et al. [20] noted that the design of workplaces can help eliminate or reduce some of the barriers known to limit physical activity at work. This is consistent with the current thinking that the environment where people live, work and learn should be designed in such a way that they can encourage physical movement and mobility [21] including walking, standing, and exercising throughout the day $[5,6,22,23,24]$. The foregoing notwithstanding, the review of literature reveals that the design of workplaces such as office buildings seems to place more emphasis on functional space and thermal comfort issues as well as measures that can increase work efficiency and productivity in repetitive tasks. In a developing country like Nigeria, apart from a study by Oyeyemi et al. [13] that sought to investigate sedentary life style and the health of occupants of buildings, no study identified by the authors has examined sedentary behaviour among office workers. In addition, although studies exist on the various kinds of interventions for sedentary behaviour in workplace in the different countries, very little research attempt has been made to investigate such interventions in the Nigerian work environment. This leaves a gap in understanding of the extent to which office buildings in this country are discouraging sedentary behaviour among the working population and the specific architectural design and spatial planning interventions for curbing this in work environment. This study is based on the premise that differences in socio-economic and environmental variables between Nigeria and other countries can be sources of variations in building design and planning interventions for sedentary behaviour in office environment; and thus the Nigerian dimension to this needs to be thoroughly investigated.

It was against this background that this research investigated sedentary behaviour among workers in selected office buildings in Enugu metropolis, Nigeria, with a view to improving understanding of the architectural design and planning interventions that can encourage workers to engage more in physical activity in the course of their daily work. The key research question addressed in this study is- How can the architectural design of workplace play a proactive role in encouraging individuals to be more physically active in their daily occupation? The three specific objectives pursued include to 1) to identify the different spatial layouts and features of office spaces in selected office buildings in Enugu metropolis, Nigeria 2) examine sedentary behaviour and physical activity among workers in selected offices in the study area; and 3) assess the differences in the level of physical activity workers in the different office layouts and features are engaged in the study area. This study makes a contribution to scientific knowledge by improving understanding of the sedentary behaviour among office workers in Enugu, Nigeria. It also adds to the growing body of knowledge on the architectural design and spatial planning interventions that could help in discouraging sedentary behaviour among office workers. To this end, it is expected that the findings of this research will inform building design professionals of some key aspects that require strengthening in the design and planning of office buildings that discourage sedentary behaviour and at the same time enhance the productivity and health of the working population.

\section{Literature Review}

\subsection{Sedentary Behaviour and Associated Health Risks}

The review of published literature reveals that the concept of sedentary behaviour (SB) or sedentary lifestyle (SLS) has been defined in several ways by different authors. For examples, Waters et al. [25] described sedentary behaviour to be synonymous with prolonged sitting behaviour, including sitting or lying down that expends low metabolic energy of between 1.0 and 1.80 metabolic equivalents. Other authors $[3,26]$ have also described sedentary behaviour as low energy expending 
behaviour-sitting or reclining posture, commonly experienced at work, long distance travelling and recreation/leisure activities. These definitions suggest that sedentary behaviour includes continuous sitting and lying, sitting with computer at work, sitting while commuting, leisure activities, screen/TV viewing, standing still, and other low energy expenditure activities [27].

The Australian Department of Health [28] also revealed that there is a difference between sedentary behaviour and physical inactivity. They made it clear that whereas being physically inactive may suggest that an individual lacks physical activity or exercise in his/her daily life, sedentary behaviour involves engaging in sitting or lying for an extended period of time. Research has shown that sedentary behaviour, particularly at work has been on the increase in recent years due to the deployment of modern technology to support the execution of tasks hitherto done manually via physical movement of parts of human body and changing of working positions $[29,30]$. As a result, there has been a gradual shift of emphasis from work that requires moderate/vigorous physical activity (MVPA) such as manufacturing to low-activity occupations in the service industries $[18,31,32]$. It is perhaps in response to the health risk directly or indirectly linked to sedentary behaviour and the increasing number of people working either in sitting or standing positions for several hours that researchers are focusing attention on the strategies for reducing occupation-related sedentary behaviour.

Previous studies have also shown that although sedentary workers may experience less exposure to some of the hazards associated with more physically demanding work [30], they are susceptible to health risks that come with clerical, administrative or managerial work that involve sitting on the computer for a long period of time $[2,33]$. Evidence in the literature has linked sedentary behaviour to reduced life expectancy [34], mortality $[10,35]$ heart- related diseases $[10,34,36]$, type 2 diabetes [36], ovarian, colon and breast cancer $[10,36]$ and endometrial cancer [36]. This means that people engaged in occupations that promote sedentary behaviour are more susceptible to these health risks than those in works that require moderate or vigorous physical activity; and thus there is a need for further research on how to ameliorate this situation using workplace design strategies.

\subsection{Architectural Design of Workspaces and Sedentary Behaviour}

Research literature has established that the built environment and structural design strategies can influence human behaviour and promote healthy living and work practices $[37,38]$. As it relates to work environment, it is known that a number of factors, including personal habits, level of occupational physical activity, or the availability of certain office design and furniture can influence sedentary behaviour among office workers [25]. Based on this, knowledge of office design seems to revolve around issues of workers' health, satisfaction and well-being [39]; indoor air quality and sick building syndrome" and other factors that seem to influence the health of office workers [40]. Using the level of physical activity involved as a criterion, the following four types of occupational groups have been identified:1) sedentary work in the office, 2) light occupational physical activity, that is work that require walking; 3) moderately heavy occupational physical activity, that is work that requires much walking and lifting), and 4) heavy occupational physical activity, which is heavy manual labour [41]. Following from this classification and increasing number of the workforce engaged in sedentary occupations, Marcela [27] explained that psychological, social, environmental and mixed approach interventions aimed at reducing sedentary behaviour or lifestyle have been identified. Among these approaches, Owen et al. [26] alluded that environmental design interventions, which include spatial manipulations of the built environment such as office workspace design (layout) and artwork installation among others, have continued to attract research attention globally.

Talking about office workspace design, a review of historical trend in the design of office layouts presented by Hascher et al. [39] revealed that the design of office spaces has evolved from the 'hot-desking' concept of the Ancient Egyptian architecture of around $5^{\text {th }}$ Century BC that encouraged mobile working and non-personalized desk use to the segregated office space-use of the $18^{\text {th }}$ and $20^{\text {th }}$ centuries, that promotes the use of largely cellular to open plan office layout. It was specifically reported that between 1900 and 1930, emphasis in productivity and working efficiency discouraged workers' movement and interactions and that this persisted until the 1950s when a new model of interior office design that came with flexibility of office space use emerged. However, with the advent of the notion of "your work is where you are", the development of office spaces in which work followed different patterns and alternative ways of performing office tasks triggered a paradigm shift resulting to the so called 'alternative officing" concept. This concept encourages mobile working outside of the fixed office space in places such as Internet cafés, homes, hotels, and other unconventional office spaces.

Hascher et al. [39] noted that the various concepts associated with workplace design are still evolving and that physical office space was becoming a layout setting that encourages sedentary behaviour. In view of this, evidence [42] shows that changes in the ergonomic design of offices and workstations are responding to the need for movement behaviour during the working hours. These changes, according to Marcela [27], can be categorized into two main types: peripheral and planning interventions. Whereas the peripheral intervention encompasses temporary spatial environment improvements such as the use of furniture, including artwork in staircases, promotional signage, and adjustable sit-stand desks to increase physical movement; the spatial planning 
intervention involves a systematic approach in promoting physical activity, which include zoning of activities to promote more movement by workers. In the interior environment, these spatial planning interventions are interpreted to mean the flow of spaces, such as strategic placement of stairs or corridor spaces, elevators and adjacent enclosed fire exit stairs or visible from entrances, the placement of stairs near elevators or visible from entrances as explained by Marcela [27]. The foregoing is consistent with the earlier submission by Van et al. [43] suggesting that spatial planning layouts can play a pivotal role in reinforcing flow of traffic and people from one space to another within the work environment.

Further, Buckley et al. [2] have explained that in office environment, a number of barriers to reducing sedentary behaviour include small/enclosed cubicle spaces, high availability and dispersion of printers and chairs and lack of adjustable workstations. This was corroborated by previous authors who reported that closeness of shared spaces to individual seats in office settings positively correlated with sedentary behaviour, and thus such design/ spatial planning strategies should be discouraged in office buildings [44]. In contrast, the strategies for reducing sedentary behaviour in office buildings include the provision of adjustable workstations, having more open office floor plan that engenders movement and centralizing of office facilities and resources. It was on this premise that Marcela [27] insisted that building and workplace design strategies, which include understanding the distribution of spaces and how these spaces can efficiently support workplace movement are key to reducing sedentary behaviour among office workers. The current study is therefore focused on efforts at identifying some proactive architectural design interventions that can promote greater physical activity and reduce the risk factors associated with sedentary behaviour among office workers.

\section{Materials and Methods}

The study area purposively selected for this research is Enugu metropolitan area. This is part of the capital territory of Enugu State, southeast Nigeria, created on the $27^{\text {th }}$ August 1991. It is located between the latitude $6^{\circ} 30^{1} \mathrm{~N} 7^{\circ} 30^{1} \mathrm{E}$ [45]. With a population of about $5,590,513$ million people, Enugu State has a population density of two and half times the national average of 226 per $\mathrm{Km}^{2}$ [46]. Enugu has a well-drained soil, good climate with a mean daily temperature of $26.7{ }^{\circ} \mathrm{C}\left(80.1^{\circ} \mathrm{F}\right)$ and the average annual rainfall of around 2,000 millimetres (79 inches) and located at about 223 meters $(730 \mathrm{ft})$ above sea level [47].

The research design adopted for this study was a cross-sectional survey, which involved quantitative research strategy. The research population comprised workers in office buildings within Enugu metropolis. The categories of offices covered were located in commercial, corporate, universities and factory buildings. The random sampling technique was used to select office workers based on their willingness and availability to participate in the survey. In view of the lack of access to a reliable database on the actual number of office workers in the study area, the sample size for the survey was estimated using the formula for infinite population developed by Cochran in 1963 given as:

$$
\mathrm{n}_{0}=\mathrm{Z}^{2} \mathrm{pq} / \mathrm{e}^{2}
$$

Where $\mathrm{n}_{0}$ is the minimum sample size, $\mathrm{Z}$ is the critical value, which is at $95 \%$ level of confidence, and in this case it is $1.96 ; p$ is $0.5 ; \mathrm{q}=1-p$, while $e$ represents the desired level of precision in the statistical estimates, which in this research is $5 \%$. In choosing the parameters used in this formula, it was assumed that there was maximum variability in the population of office workers manifesting sedentary behaviour in the study area. Using this formula, 385 participants were estimated as the sample size for the survey.

The primary data collection instrument used was a structured questionnaire designed by the researchers specifically for this study. The questionnaire was structured to capture data on the following aspects: demographic characteristics of the workers; characteristics of buildings where their offices are located, number of workers in the office, number of hours spent in the office and spatial features of the offices as well as the sedentary behaviour and physical activity of the workers. The questions in the questionnaire were mainly closed-ended in nature. The questionnaire was subjected to review by experts and pre-tested to enhance the validity of findings of this research. Reliability of the scale of measurement for sedentary behaviour and physical activity of the workers was examined using Cronbach's alpha reliability tests and the result returned 0.867 , which is greater than the 0.6 recommended as the minimum acceptable value.

The survey took place between August and November 2018. This involved administration of copies of the questionnaire to randomly selected 385 office workers. Three trained research assistants were engaged in the questionnaire administration and retrieval. However, 106 representing around $27.53 \%$ of the total number retrieved were correctly completed and included in the analyses. The data collected were analysed using the SPSS version 23 for windows. Due to the nature of the three research objectives stated in introduction part of this paper and the type of data collected, descriptive statistics which include frequencies and percentages were used to summarize the categorical variables, while means and standard deviations were used for continuous variables. Comparison of means of continuous variables was done using ANOVA and Duncan multiple comparison test. P-value less than 0.05 was regarded as significant. Duncan multiple comparison test was used in the data analysis because it helped in identifying significance levels of the difference between 
pair of means investigated. Specifically, it was useful in comparing larger pairs of mean values of work time spent on physical activity by workers in different office layouts and features using tables. The results obtained from the analyses are presented in tables in the next section of this paper.

\section{Results and Discussion}

\subsection{Demographic Characteristics of the Respondents}

Results of the descriptive analysis reveal that about $55.7 \%$ of the office workers who participated in the survey were males, while $44.3 \%$ were females and that the office workers were predominantly within the age bracket of 30 years and 54 years and most (93.2\%) of them were highly educated as they have either a first degree or a higher degree (Table 1).

Table 1. Demographic characteristics of the respondents

\begin{tabular}{|c|c|c|}
\hline & Frequency $n=106$ & Percent \\
\hline \multicolumn{3}{|l|}{ Gender } \\
\hline Male & 59 & 55.7 \\
\hline Female & 47 & 44.3 \\
\hline \multicolumn{3}{|l|}{ Age range in years } \\
\hline $20-24$ & 4 & 3.8 \\
\hline $25-29$ & 9 & 8.5 \\
\hline $30-34$ & 14 & 13.2 \\
\hline $35-39$ & 10 & 9.4 \\
\hline $40-44$ & 14 & 13.2 \\
\hline $45-49$ & 26 & 24.5 \\
\hline $50-54$ & 20 & 18.9 \\
\hline $55-59$ & 8 & 7.5 \\
\hline 60 and above & 1 & .9 \\
\hline \multicolumn{3}{|l|}{ Educational qualification } \\
\hline GCE/WAEC O’Level & 2 & 1.9 \\
\hline $\mathrm{OND} / \mathrm{NCE}$ & 2 & 1.9 \\
\hline HND/ Bachelor degree & 44 & 41.5 \\
\hline Higher degrees & 58 & 54.7 \\
\hline
\end{tabular}

These results indicate that most of the participants in the survey are middle-age workers who constitute the bulk of active working population in the study area (Table 1). In addition, the results also show that most of the workers sampled are highly educated persons, which is not a surprise because most office workers in the study area in particular and Nigeria in general are usually highly-educated persons engaged in white collar jobs.

\subsection{Characteristics of the Office Buildings and Spaces}

Results of the descriptive analysis of the characteristics of the buildings from where the office workers who participated in the survey were sampled revealed that most (75.5\%) of the buildings were built specifically as office buildings and about one-third were between 5 years and 25 years old and most of them were multi-storey buildings with about one-half $(50.9 \%)$ being 2-storey and 4-storey buildings (Table 2). As expected, the means of vertical circulation in the buildings were mainly staircases $(81.1 \%)$ and in $74.5 \%$ of the buildings, between one worker and 10 workers were found per office space and more than-half $(52.8 \%)$ of the workers indicated that they spent an average time of between 4 hours and 6 hours per day in the office buildings (see Table 2).

Table 2. Building characteristics

\begin{tabular}{|c|c|c|}
\hline Variable options & Frequency & Percent \\
\hline \multicolumn{3}{|l|}{ Building type } \\
\hline Purpose built commercial building & 12 & 11.3 \\
\hline Purpose built office building & 80 & 75.5 \\
\hline Remodelled flat & 5 & 4.7 \\
\hline Remodelled maisonette & 2 & 1.9 \\
\hline Rented apartment & 7 & 6.6 \\
\hline \multicolumn{3}{|l|}{ Age of building } \\
\hline Incomplete & 2 & 1.9 \\
\hline $1-5$ years & 9 & 8.5 \\
\hline 5-25years & 34 & 32.1 \\
\hline More than 25years & 28 & 26.4 \\
\hline Not sure & 33 & 31.1 \\
\hline \multicolumn{3}{|l|}{ Length of stay in the building } \\
\hline More than 10years & 33 & 31.1 \\
\hline 5-10years & 24 & 22.6 \\
\hline 2-5years & 31 & 29.2 \\
\hline Under 2years & 16 & 15.1 \\
\hline Others & 2 & 1.9 \\
\hline \multicolumn{3}{|l|}{ How many stories high } \\
\hline 1story high & 22 & 20.8 \\
\hline 2-4story high & 54 & 50.9 \\
\hline 5-story high and above & 28 & 26.4 \\
\hline Others & 2 & 1.9 \\
\hline \multicolumn{3}{|l|}{ Means of vertical circulation } \\
\hline Staircase & 86 & 81.1 \\
\hline Lift & 4 & 3.8 \\
\hline Staircase and lift & 16 & 15.1 \\
\hline \multicolumn{3}{|l|}{ Number of people in your office } \\
\hline $1-10$ & 79 & 74.5 \\
\hline $11-20$ & 8 & 7.5 \\
\hline $21-30$ & 9 & 8.5 \\
\hline$>30$ & 10 & 9.4 \\
\hline \multicolumn{3}{|l|}{$\begin{array}{c}\text { Average of time spent in the office } \\
\text { building in hours }\end{array}$} \\
\hline $2-3$ & 1 & 0.9 \\
\hline $4-6$ & 56 & 52.8 \\
\hline $7-10$ & 45 & 42.5 \\
\hline Not sure & 4 & 3.8 \\
\hline
\end{tabular}

The results generally show that most of the buildings 
sampled were purpose built multi-storey office buildings of over 5 years old with stairs as the predominant vertical circulation elements (Table 2). The buildings were also found to have been in use as offices for over 5 years and the average time most of the users spent in their offices was between 4 hours and 10 hours in a day. The general characteristics of the buildings sampled may have implications for sedentary behaviour of the workers who use them. The result on the number of hours the workers spent in their offices is line with evidence $[17,18,19]$ indicating that many office workers spend most of their time working in their offices.

The descriptive analysis of the features of the offices in the buildings sampled also reveals that the predominant type of office was private office (35.8\%) and co-working office (36.8\%) (Table 3). Consequently, personalized office layout (35.8\%) and co-working office layout (26.4) were the most predominant types of office layouts identified in the survey. Most of the offices were either linked directly by doors $(32.1 \%)$ or passages $(43.4 \%)$ as indicated in Table 3.

Table 3. Office features

\begin{tabular}{|c|c|c|}
\hline Variables & $\begin{array}{l}\text { Frequency } \\
\mathrm{n}=106\end{array}$ & Percent \\
\hline \multicolumn{3}{|l|}{ Type of office } \\
\hline Private office & 38 & 35.8 \\
\hline Mixed use office & 24 & 22.6 \\
\hline Co-working office & 39 & 36.8 \\
\hline Others & 5 & 4.7 \\
\hline \multicolumn{3}{|l|}{ Type of office layout } \\
\hline Personalized office layout & 38 & 35.8 \\
\hline Low partition office layout & 21 & 19.8 \\
\hline Co-working office layout & 28 & 26.4 \\
\hline Open plan office layout & 19 & 17.9 \\
\hline \multicolumn{3}{|l|}{ Features that best fit your office space } \\
\hline $\begin{array}{l}\text { Office space, TV lounge, conference, } \\
\text { in-suit W.C, coffee/snakes, CCTV } \\
\text { monitor }\end{array}$ & 4 & 3.8 \\
\hline $\begin{array}{l}\text { Office space, conference, in-suit W.C, } \\
\text { CCTV monitor, TV }\end{array}$ & 10 & 9.4 \\
\hline $\begin{array}{l}\text { Office space, meeting area, in-suit } \\
\text { W.C, TV }\end{array}$ & 32 & 30.2 \\
\hline $\begin{array}{l}\text { Office space, meeting area, grouped } \\
\text { convenience }\end{array}$ & 27 & 25.5 \\
\hline Office space, grouped convenience & 33 & 31.1 \\
\hline \multicolumn{3}{|l|}{ Existing link in your office space } \\
\hline Direct by door & 34 & 32.1 \\
\hline Walk-in closet & 8 & 7.5 \\
\hline Passage & 46 & 43.4 \\
\hline Lobby & 13 & 12.3 \\
\hline No link & 5 & 4.7 \\
\hline
\end{tabular}

The results showing a significant proportion of private office and co-working office as well as personalized office and co-working office layouts as the most predominant types of office layouts identified in the survey appears to be consistent with the findings by Hascher [39] on the prevailing office layouts in contemporary times. On the one hand, the evidence showing the features that best describe the office spaces of the workers to include work stations, TV lounge, conference, in-suit W.C, coffee/snakes, CCTV monitor among others, is suggestive of office environment that can encourage sedentary behaviour such as continuous sitting and lying, sitting with computer at work, sitting and other low energy expenditure activities as previously highlighted by Marcela [27]. Similarly, evidence of offices spaces having meeting areas and grouped conveniences in the office buildings sampled on the other hand appears to be consistent with the submission by Buckley et al. [2] suggesting that having centralized meeting spaces and sharing office resources can help reduce sedentary behaviour in office workers.

\subsection{Sedentary Behaviour and Physical Activity among the Workers}

Table 4 shows the results of sedentary behaviour and physical activity among the workers sampled in the survey.

Table 4. Sedentary behaviour and physical activity among workers

\begin{tabular}{|c|c|c|}
\hline & Mean \pm SD & \% Change \\
\hline Sedentary activity (Sitting) & $374.91 \pm 49.63$ & $93 \%$ \\
\hline Light activity (Standing) & $20.53 \pm 6.99$ & $5 \%$ \\
\hline Moderate Activity & $8.16 \pm 3.34$ & $2 \%$ \\
\hline
\end{tabular}

The results reveal that the workers sampled spent more time sitting at workplaces (374.91) which amounts to around $93 \%$ of the total time they spent at work, while they spent an average of 21 minutes standing, which is about $5 \%$ of the total time they spent at work, while just $2 \%$ of the total time at work is spent on moderate activity (see Table 4). Going by the different categories of work previously identified by Graff-Iversen et al. [41], these results suggest that the workers sampled are involved in two main categories of work: sedentary work and work that involves light occupational physical activity such as walking, while they engage very little in work that requires moderately physical activity such as walking and lifting and do not engage in work involving heavy physical activity such as manual labour (Table 4). These findings appear to be in line with that from previous research [see for examples 17, 18, 19] showing that for many office workers, occupational sitting time contributes at least $50 \%$ of their daily sitting time, with many sitting for more than three-quarters of their work day, which is a key aspect sedentary behaviour in workplaces.

Furthermore, the results of mean work time spent on physical activity by workers in the different office layouts indicate that the average time spent by workers in the different office layouts on physical activities were 
significantly different at $\mathrm{p}<0.001$ (Table 5 ). These results also show that workers in personalized offices spent significantly longer time sitting, followed by workers in low-partitioned offices, co-working offices, and open-plan offices, respectively. The reverse was the case for light activity (standing). However, moderate activity was only performed by workers in co-working and open-plan offices. Workers in open-plan offices spent significantly higher time on moderate activity $(\mathrm{p}<0.001)$ (See Table 5). These results generally show that workers in personalized offices spent more time siting than those in other office layouts, while those in open plan office layouts spent the least time sitting. This result provides support to the finding in a previous research indicating that closeness of shared spaces to individual seats in office settings was positively correlated with sedentary behaviour among workers [see 35].

The results in Table 6 are the comparison of mean work time spent on physical activity by workers in the different office spaces and features. The results reveal that the average time spent by workers in the different office features on physical activities (sitting and standing) was significantly different at $p<0.05$. The Duncan multiple comparison indicates that workers in office spaces with grouped convenience spent significantly lower time on sedentary activity (sitting) compared to those in office spaces with in-suit toilet facilities, lounge and conference areas $(\mathrm{F}=4.134, \mathrm{p}=0.004)$. The reverse was the case for light activity (standing), $(\mathrm{F}=2.968, \mathrm{p}=0.023)$. However, moderate activity was reported only among workers in office spaces with grouped conveniences and this was not statistically significant $(\mathrm{F}=0.317, \mathrm{p}=0.813)$ as shown in Table 6.

The results in Table 6 suggest that working in office spaces where there are shared facilities such as conveniences can significantly lower time on sedentary activity (sitting) by encouraging light activity such as standing and walking, while working in office spaces with in-suit WC, lounge and conference areas promotes sedentary behaviour by reducing the level of walking workers can engage in carrying out their tasks. These findings are in line with the suggestions as they relate to the design of offices that discourage sedentary behaviour in workers [see 24, 49]. Furthermore, the study carried out comparative analysis of mean work time spent on physical activity by workers in the different office linkages and the results are presented in Table 7 . The results generally show that the average time spent by workers in offices with different linkages, on physical activities (sitting and standing) was significantly different at $\mathrm{p}<0.05$. Moreover, workers in offices linked directly by doors significantly spent more time on sedentary activity (sitting) followed by those in offices with walk -in closet, passages, lobbies and no link in that order $(\mathrm{F}=2.933, \mathrm{p}=0.024)$ (Table 7). This implies that the group of workers who spent more time on sedentary activity have direct doors linked to their offices and private conveniences. This suggests that they may be more exposed to some of the health risks associated with sedentary behaviour such as reduced life expectancy, heart- related disease, type 2 diabetes and different types of cancer than those who spent less time on such activities as previous studies $[10,34,36,50]$ have indicated. However, Duncan multiple comparison tests indicate that time spent in offices with linkages such as passages and lobbies was not significantly different. The reverse was the case for light activity $(\mathrm{F}=4.258, \mathrm{p}=0.003)$. The results also indicate that the time spent standing were not significantly different in offices with walk-in closets, passages and lobbies. However, moderate activity was not statistically significant for the linkages $(\mathrm{F}=1.608, \mathrm{p}=$ 0.192), (see Table 7).

It can be inferred from the foregoing results that the design, spatial planning and features of the office spaces are among the key factors that can influence the level of physical activity (e.g. sitting, standing, walking) engaged in by the workers sampled. This appears to corroborate the findings from previous studies indicating that the built environment and structural design strategies can impact human behaviour [see 37, 38].

The results of comparison of mean work time spent on physical activity by workers in the different office type show that the average time spent by workers in commercial workplaces on sedentary activity (sitting) was significantly higher, followed by those in cooperate workplaces, universities, and factories, respectively $(\mathrm{F}=$ 4.624, $\mathrm{p}=0.004)$ (Table 8). The reverse was the case for light activity $(\mathrm{F}=5.456, \mathrm{p}=0.002)$. Notably, factory workers included in the sample spent significantly longer time performing moderate activity tasks than workers in other type of workplaces $(\mathrm{F}=5.183, \mathrm{p}=0.003)$ (Table 8$)$. These results suggest that on the one hand, workers in the commercial sector spent more time sitting than their counterparts who work in offices belonging to corporate organizations, universities and factories. On the other hand, factory workers spent more time in work involving standing and moderate activities such as walking than those that work in universities, corporate and commercial office buildings in the study area. These results seem to provide support to the assertion by Genin et al. [8] indicating that the nature of work can promote sedentary behaviour in workers. They are also consistent with the submission by previous authors [e.g. 2, 33] suggesting that people who are engaged in clerical, administrative or managerial work in corporate, commercial and service-oriented industries that necessitates sitting on the computer for a long period of time tend to manifest sedentary behaviour than those who are engaged in physically demanding work in the manufacturing sector such as factories. 
Table 5. Comparison of mean work time spent on physical activity by workers in different office layout

\begin{tabular}{|c|c|c|c|c|c|c|}
\hline \multirow{2}{*}{$\begin{array}{c}\text { Intensity level } \\
\text { (min/day) }\end{array}$} & \multicolumn{2}{|c|}{ Office Layout } & Personalized \\
\cline { 2 - 7 } & $\begin{array}{c}\text { Low partition } \\
\text { Mean } \pm \text { SD }\end{array}$ & $\begin{array}{c}\text { Co-working } \\
\text { Mean } \pm \text { SD }\end{array}$ & $\begin{array}{c}\text { Open plan } \\
\text { Mean } \pm \text { SD }\end{array}$ & F & P value \\
\hline $\begin{array}{c}\text { Sedentary } \\
\text { Activity (Sitting) }\end{array}$ & $431.11 \pm 12.47$ & $372.81 \pm 23.14$ & $339.04 \pm 19.21$ & $317.68 \pm 27.72$ & 184.445 & $<0.001$ \\
\hline $\begin{array}{c}\text { Light Activity } \\
\text { (Standing) }\end{array}$ & $12.92 \pm 2.11$ & $19.29 \pm 1.87$ & $24.75 \pm 1.17$ & $30.89 \pm 2.18$ & 453.126 & $<0.001$ \\
\hline $\begin{array}{c}\text { Moderate } \\
\text { Activity } \\
\text { (walking and } \\
\text { lifting) }\end{array}$ & - & - & $5.60 \pm 0.76$ & $11.53 \pm 2.19$ & 158.078 & $<0.001$ \\
\hline
\end{tabular}

Table 6. Comparison of mean work time spent on physical activity by workers in different office space and features

\begin{tabular}{|c|c|c|c|c|}
\hline $\begin{array}{l}\text { Intensity level } \\
(\text { min/day })\end{array}$ & Office features & Mean \pm SD & $\mathbf{F}$ & P-value \\
\hline \multirow{5}{*}{$\begin{array}{c}\text { Sedentary Activity } \\
\text { (Sitting) }\end{array}$} & $\begin{array}{l}\text { Office space, TV lounge, conference, in-suit w.c, } \\
\text { coffee/snacks, CCTV monitor }\end{array}$ & ${ }^{\mathrm{a}} 395.50 \pm 62.38$ & & \\
\hline & Office space, conference, in-suit WC, CCTV monitor, TV & a $391.25 \pm 21.75$ & 4.134 & 0.004 \\
\hline & Office space, meeting area, in-suit WC TV & $\mathrm{b}_{3} 36.47 \pm 45.31$ & & \\
\hline & Office space, meeting area, grouped convenience & ${ }^{\mathrm{b}} 384.37 \pm 52.06$ & & \\
\hline & Office space, grouped convenience & ${ }^{b} 347.73 \pm 40.18$ & & \\
\hline \multirow{5}{*}{$\begin{array}{l}\text { Light Activity } \\
\text { (Standing) }\end{array}$} & $\begin{array}{l}\text { Office space, TV lounge, conference, in-suit w.c, } \\
\text { coffee/snacks, CCTV monitor }\end{array}$ & ${ }^{\mathrm{a}} 18.25 \pm 3.09$ & & \\
\hline & Office space, conference, in-suit WC, CCTV monitor, TV & ${ }^{\mathrm{a}} 17.70 \pm 7.65$ & 2.968 & 0.023 \\
\hline & Office space, meeting area, in-suit WC, TV & ${ }^{\mathrm{a}} 18.59 \pm 6.92$ & & \\
\hline & Office space, meeting area, grouped convenience & $\mathrm{b}_{2} 20.41 \pm 7.58$ & & \\
\hline & Office space, grouped convenience & $\mathrm{b}_{2} 23.64 \pm 5.75$ & & \\
\hline \multirow{5}{*}{ Moderate Activity } & $\begin{array}{l}\text { Office space, TV lounge, conference, in-suit w.c, } \\
\text { coffee/snacks, CCTV monitor }\end{array}$ & - & & \\
\hline & office space, conference, in-suit WC, CCTV, monitor, TV & - & & \\
\hline & Office space, meeting area, in-suit w.c, TV & - & & \\
\hline & Office space, meeting area, grouped convenience & $8.54 \pm 3.82$ & 0.317 & 0.813 \\
\hline & Office space, grouped convenience & $8.44 \pm 3.35$ & & \\
\hline
\end{tabular}

a,b Duncan multiple comparison indicating means not significantly different

Table 7. Comparison of mean work time spent on physical activity by workers in different office linkages

\begin{tabular}{|c|c|c|c|c|}
\hline Intensity level (min/day) & Existing Link & Mean & $\mathbf{F}$ & $P$ value \\
\hline \multirow[t]{5}{*}{ Sedentary activity (Sitting) } & Direct by door & $391.57 \pm 48.74$ & & \\
\hline & Walk-in closet & $367.76 \pm 41.81$ & 2.933 & 0.024 \\
\hline & Passage & a $359.15 \pm 43.70$ & & \\
\hline & Lobby & ${ }^{\mathrm{a}} 358.50 \pm 63.45$ & & \\
\hline & No link & $337.40 \pm 63.24$ & & \\
\hline \multirow[t]{5}{*}{ Light activity (Standing) } & Direct by door & $12.91 \pm 6.81$ & & \\
\hline & Walk-in closet & ${ }^{\mathrm{a}} 21.55 \pm 5.87$ & 4.258 & 0.003 \\
\hline & Passage & ${ }^{\mathrm{a}} 22.50 \pm 7.93$ & & \\
\hline & Lobby & ${ }^{\mathrm{a}} 23.00 \pm 6.38$ & & \\
\hline & No link & $28.00 \pm 7.71$ & & \\
\hline \multirow[t]{5}{*}{ Moderate activity (Walking) } & Direct by door & - & & \\
\hline & Walk-in closet & - & 1.608 & 0.192 \\
\hline & Passage & $7.00 \pm 2.52$ & & \\
\hline & Lobby & $9.75 \pm 3.30$ & & \\
\hline & No link & $11.25 \pm 2.50$ & & \\
\hline
\end{tabular}


Table 8. Comparison of mean work time spent on physical activity by workers in different office type

\begin{tabular}{|c|c|c|c|c|c|c|}
\hline & \multicolumn{5}{|c|}{ Type of workplace } & Factory \\
& $\begin{array}{c}\text { Commercial } \\
\text { Mean } \pm \text { SD }\end{array}$ & $\begin{array}{c}\text { Corporate } \\
\text { Mean } \pm \text { SD }\end{array}$ & $\begin{array}{c}\text { University } \\
\text { Mean } \pm \text { SD }\end{array}$ & F & P value \\
\hline $\begin{array}{c}\text { Sedentary } \\
\text { Activity } \\
\text { (Sitting) }\end{array}$ & $399.69 \pm 52.54$ & $376.77 \pm 47.32$ & $361.81 \pm 41.15$ & $356.68 \pm 44.72$ & 4.624 & 0.004 \\
\hline $\begin{array}{c}\text { Light Activity } \\
\text { (Standing) }\end{array}$ & $17.17 \pm 6.82$ & $23.55 \pm 6.29$ & $50.63 \pm 7.04$ & $70.53 \pm 6.39$ & 5.456 & 0.002 \\
\hline $\begin{array}{c}\text { Moderate } \\
\text { Activity }\end{array}$ & ${ }^{\mathrm{a}} 7.63 \pm 3.16$ & ${ }^{\mathrm{a}} 8.33 \pm 3.55$ & ${ }^{\mathrm{a}} 10.00 \pm 2.94$ & $30.09 \pm 3.24$ & 5.183 & 0.003 \\
\hline
\end{tabular}

\section{Conclusions and Recommendations}

In this research, sedentary behaviour among workers in selected office buildings in Enugu metropolis, Nigeria, was investigated with a view to improving understanding of the architectural design and planning interventions that can encourage workers to get involved in physical activity such as walking and standing in the course of their daily work. The findings are very incisive and illuminating and have culminated in the following specific conclusions and recommendations. First, the findings related to the first objective indicate that the predominant office layouts in the study area were personalized and co-working office layouts that are either directly linked by doors or passages/lobbies and have either personalised or grouped conveniences, facilities and resources. The implication of this is that the office layouts and features have the tendency to promote sedentary behaviour because they tend to limit the movement of workers by encouraging them to sit more and stand and walk less in the course of their daily work. Second, the findings from the second research objective revealed that the workers sampled usually spent around $93 \%$ of the total time at work sitting, $5 \%$ of the total time at work standing and $2 \%$ of the total time at work performing moderate activity. This implies that the workers predominantly manifest sedentary behaviour at work. This is not very good for their health and well-being as this has the tendency to expose them to several health risks associated with sedentary lifestyle as previously highlighted in this paper.

Third, the findings of this research also revealed that there are differences in the level of physical activity among the workers in the different office layouts and offices having various features. In fact, it was observed that workers in personal office layout manifested sedentary behaviour more than those in co-working and open plan office layouts. Based on this finding, it can be inferred that in order to discourage sedentary behaviour among office workers, the design of office spaces should be based on co-working and open-plan layouts with significant centralisation of office resources so that workers will be compelled to stand and walk intermittently in the course of their daily activities. This means that if the goal is to discourage sedentary behaviour in workers, the design of offices with private conveniences and facilities should be discouraged as much as possible. This call for architectural design strategies that promote grouping of conveniences and resources in office buildings. In addition, spatial planning that encourages snacking, toileting, photocopying, meeting with superiors, walking up to colleagues, walking up to meet appointment in visitor's room and the use of staircases should be encouraged in the design of office spaces.

The study also found that workers in offices owned by commercial and corporate entities as well as universities engaged more in sedentary behaviour than their counterparts who work in factories. In view of this, it is recommended that architects and other building professionals involved in the design and development of office buildings for commercial and corporate organizations as well as universities should adopt building design strategies that promote co-working and open plan office layouts and sharing of office resources among workers. For example, office spaces with in-suit toilet facilities, private lounges and conference areas known to engender sedentary behaviour by encouraging sitting for a long period of time with potential health risks should be avoided as much as possible. Following from this, it is suggested that future office spaces should not have direct door links, rather lobbies and corridors should be used in the design of office buildings to ensure that workers engage in physical activity such as standing and walking in the course of daily work activities.

Although this study attempted to address the key research question stated, it cannot be said to have no limitations. In the first instance, since the data were sourced mainly via the administration of questionnaire, the findings are limited to the biases of the respondents. It is suggested that future study be carried out on this subject and such study should consider analysing the design and planning of office buildings and observing workers' movement in order to circumvent the shortcomings of questionnaire survey used in the current study. Second, the study is also limited to the number of participants and the study area. Hence, it is also suggested that further study be conducted to include more participants beyond 
the geographic coverage of the current study.

\section{REFERENCES}

[1] European Commission press. Indoor air pollution: new EU research reveals higher risks than previously thought. 2003 Retrieved from http://europa.eu/rapid/press-release_IP-03-1 278_en.htm/; US Environmental Protection Agency (USEPA)/Office of Air and Radiation, The inside story: A guide to indoor air quality. Office of Radiation and Indoor Air. Retrieved August 8, 2020 from http:/www.epa.gov/iaq /pubs/insidestory.html/.

[2] J.P. Buckley, A, Hedge, T. Yates, R.J. Copeland, M. Loosemore, M. Hamer, D.W. Dunstan. The sedentary office: a growing case for change towards better health and productivity. British Journal of Sports Medicine. Vol. 49, No 21, pp.1357-62, 2015.Doi:10.1136/bjsports-2015-094618.

[3] R. R, Pate, J.R. O’Neill, F. Lobelo. The Evolving Definition of 'Sedentary'. Exer Sport Sci Rev, Vol.36, No. pp.173-178, 2008. Doi: 10.1097/JES.0b013e3181877d1a.

[4] S. Milunpalo. Evidence and theory of promotion of health-enhancing physical activity. Public Health Nutr, Vol.4, No. pp.725-728, 2001. Doi: 10.1079/phn2001163.

[5] A. Smith, S. Bird. From evidence to policy: reflections on emerging themes in health- enhancing physical activity. J Sports Sci, Vol. 22, pp. 791-799, 2004. Doi.org/10.1080/02640410410001712476.

[6] W.L. Haskell, I.M. Lee, R.P. Pate, K.E. Powell, S.N. Blair, B.A. Franklin. Physical activity and public health: updated recommendation for adults from the American College of Sports Medicine and the American Heart Association. Circulation, Vol.39 No. 8, pp.1423-1434, 2007. Doi: 10.1249/mss.0b013e3180616b27.

[7] World Health Organization.Global recommendations on physical activity for health. World Health Organization, Geneva, 2010.

[8] P. M. Genin, P. Dessenne, J. Finaud, B. Pereira, F. Dutheil, D. Thivel, M. Duclos. Effects of Work-Related Sedentary Time on Overall Health Profile in Active Vs Inactive Workers. Frontiers in Public Health, Vol. 6 No. 279, pp.1-8, 2018. Doi: 10.3389/fpubh.2018.00279.

[9] P. Hamar, S. Biddle, L. Soo's, B. Taka' cs, A. Husza' r. The prevalence of sedentary behaviours and Physical activity in Hungarian youth. European Journal of Public Health, Vol. 20, No. 1, pp. 85-90, 2009. DOI: 10.1093/eurpub/ckp100.

[10] A. Biswas, P. I. Oh, G.E. Faulkner, R.R. Bajaj, M.A. Silver, M.S. Mitchell, D. A. Alter. Sedentary time and its association with risk for disease incidence, mortality, and hospitalization in adults: a systematic review and meta-analysis. Annals of Internal Medicine, Vol. 162, No. 2, pp.123-132, 2015. Doi: 10.7326/M14-1651.

[11] Centers for Disease Control and Prevention. Adult participation in aerobic and muscle-strengthening physical activities - United States. Morbidity and Mortality Weekly Report, Vol 62, No.17, pp.326-329,2013.
[12] O.O. Ogwumike, B. Kaka, O. Adegbemigun, T. Abiona. Health-related and socio-demographic correlates of physical activity level amongst urban menopausal women in Nigeria. Maturitas, Vol. 73, pp. 349-353, 2012. https://doi.org/10.10 16/j.maturitas.2012.09.010.

[13] A. Oyeyemi, O. Adeyemi. Relationship of physical activity to cardiovascular risk factors in an urban population of Nigerian adults. Archives of Public Health, Vol. 71, No. 6, pp.1-9, 2013. Doi:10.1186/0778-7367-71-6.

[14] Guardian Newspaper. Nigerian Newspaper Guardian titled "why sedentary lifestyle is bad for your health" of 10th November 2018.

[15] K. Olayinka, A. Soyibo, T. Atinmo T. Impact of globalization on food consumption, health and nutrition in Nigeria. In Globalization of food systems in developing countries: impact on food security and nutrition. Paper 83 . Food and Agricultural Organization of the United Nations. 2004 http://ftp.fao.org/docrep/fao/007/y5736e/y5736e00.pdf. December 19, 2010.

[16] O. Adediran, A.A. Akintunde, A.E. Edo, O.G. Opadijo, A.M. Araoye AM. Impact of urbanization and gender on frequency of metabolic syndrome among native Abuja settlers in Nigeria. J Cardiovascular Dis Res, Vol.3, pp.191-196, 2012. Doi: 10.4103/0975-3583.98890.

[17] N. Gilson, N. Burton, J. van Uffelen, W. Brown. Occupational sitting time: Employees' perceptions of health risks and intervention strategies. Health Promot Journal Austr. Vol. 22, No 1, pp.38-43, 2011. Doi: 10.1071/he11038.

[18] C. Ryan, P. Dall, M. Granat, P. Grant P. Sitting patterns at work: Objective measurement of adherence to current recommendations. Ergonomics., Vol. 4, No. 6, pp.531-538, 2011. Doi.org/10.1080/00140139.2011.570458.

[19] A. Thorp, G. Healy, E. Winkler, B. Clark, P. Gardiner, N. Owen. Patterns of objectively-measured prolonged sedentary time and physical activity at work. Proceedings of the American College of sports medicine; May 30-2 June; Philadelphia, PA. 2012

[20] L.B. Dugdill, A. Hulme, C. McCluskey, S. A.F. Long. Workplace physical activity interventions: a systematic review. Int J Workplace Health Manage. Vol 1, No.1 pp. 20-40, 2008. Doi.org/10.1108/17538350810865578.

[21] City of New York. Active Design Guidelines: Promoting Physical Activity and Health in Design, 2010. Retrieved on July 6, 2020 from http://centerforactivedesign.org/dl/guideli nes.pdf/.

[22] B. Nordgren, C. Friden, I. Demmelmaier, G. Bergstrom, C.H. Opava. Long-term health-enhancing physical activity in rheumatoid arthritis- the PARA 2010 study. BMC Public Health, Vol. 12, No. 397, pp.1-10, 2012. Doi:10.1186/1471-2458-12-397.Doi:10.1186/1471-2458-12 -397 .

[23] T. Alkhajah, M. Reeves, E. Eakin, E. Winkler, N. Owen, G. Healy. Sit-stand workstations: A pilot intervention to reduce office sitting time. Am J Prev Med, Vol. 43, No.3, pp.298-303, 2012. Doi: 10.1016/j.amepre.2012.05.027.

[24] D. Burney, A. Claflin. Practical considerations for 
implementing research on the research on the indoor built environment. Building Research and information, Vol. 44, No.3, pp.342-344, 2016.

Doi.org/10.1080/09613218.2015.1088225.

[25] C. Waters, E. Ling, A. Chu, S. Ng, A. Chia, Y. Lim, F. Müller-Riemenschneider. Assessing and understanding sedentary behaviour in office-based working adults: a mixed-method approach. BMC Public Health, Vol.16, No.360, pp. 1-11, 2016. DOI 10.1186/s12889-016-3023-z.

[26] N. Owen, G. N. Healy, C.E. Matthews, D.W. Dunstan. Too Much Sitting. Exercise and Sport Sciences Reviews, Vol. 3, No. 3, pp.105-113, 2010.

Doi:10.1097/jes.0b013e3181e373a2.

[27] C. Marcela, Impact of Workplace Design and Planning on Sedentary Lifestyles. A Thesis Presented to the Faculty of the Graduate School of Cornell University in Partial Fulfilment of the Requirements for the degree of Master of Science, 2018.

[28] Australian Department of Health. Australia's physical activity and sedentary behaviour guidelines.2014. Retrieved on July 6, 2020 from: http://www.health.gov.au/internet/ma in/publishing.nsf/content/health-pubhlth-strategphys-act-gui delines\#apaadult.

[29] S. Parry, L. Straker. The contribution of office work to sedentary behaviour associated risk. BMC Public Health, Vol. 13, No. 296, pp.1-10,2013. Doi:10.1186/1471-2458-13 $-296$.

[30] A. Kazi, C. Haslam, M. Duncan, S. Clemes, R. Twumasi. Sedentary behaviour and health at work: an investigation of industrial sector, job role, gender and geographical differences, Ergonomics, Vol.62, No.1, pp.21-30, 2019. Doi:10.1080/00140139.2018.1489981.

[31] N.E. Sherwood, R. W. Jeffery. The Behavioural Determinants of Exercise: Implications for Physical Activity Interventions. Annual Review of Nutrition, Vol. 20, pp. 21-44, 2000. Doi: 10.1146/annurev.nutr.20.1.21.

[32] L. Straker, S. Mathiassen S. Increased physical workloads in modern work- a necessity for better health and performance? Ergonomics, Vol. 52, No.10, pp.1215-1225, 2009. Doi: 10.1080/00140130903039101.

[33] M. A. Kirk, R.E. Rhodes. Occupation correlates of adults' participation in leisure-time physical activity - a systematic review. Am J Prev Med, Vol. 40, pp.476-485, 2011. Doi: 10.1016/j.amepre.2010.12.015.

[34] K.I Proper, A.S. Singh, W. van Mechelen, M. J. M. Chinapaw. Sedentary behaviours and health outcomes among adults: A systematic review of prospective studies. Am J Prev Med, Vol. 40, pp.174-182, 2011. Doi: 10.1016/j.amepre.2010.10.015.

[35] J. Chau, A. Grunseit, T. Chey, E. Stamatakis, W. Brown, C. Matthews, A. Bauman, H.Van der Ploeg. Daily Sitting Time and All-Cause Mortality: A Meta-Analysis. PLoS ONE, Vol. 8, No.11, pp. 1-13, 2013. https://doi.org/10.1371/journal.po ne. 0080000 .

[36] L. De Rezende, M. Rodrigues Lopes, J. Rey-López, V. Matsudo, O. Luiz, O. Sedentary Behaviour and Health Outcomes: An Overview of Systematic Reviews. PLoS ONE, Vol. 9, No.8, pp.1-7 2014.
Doi:10.1371/journal.pone.0105620.

[37] T. Mcguckin, R. Sealey, F. Barnett. Planning for sedentary behaviour interventions: office workers' survey and focus group responses. Perspectives in Public Health, Vol.137, No. 6, pp.316-321, 2017. Doi: 10.1177/1757913917698003.

[38] J.P. Buckley, D.D. Mellor, M. Morris. Standing-based office work shows encouraging signs of attenuating post-prandial glycaemic excursion. Occupational and environmental medicine, Vol.71, No. 2, pp.109-11, 2014. Doi: 10.1136/oemed-2013-101823.

[39] R. Hascher, S. Jeska, B. Klauck. A design manual: Office Buildings, Birkhauser, Basel. Berlin. Boston 2002.

[40] A.F. Marmot, J. Eley, M. Stafford, E. Warwick, M.G. Marmot. Building health: an epidemiological study of sick building syndrome in the Whitehall II study. Occup Environ Med, Vol. 63, No.4, pp.283-289, 2006.Doi: 10.1136/oem.2005.022889.

[41] S. Graff-Iversen, S.A. Anderssen, I.M. Ingar M Holme, A. K. Jenum, T. Raastad. An adapted version of the long International Physical Activity Questionnaire (IPAQ-L): construct validity in a low-income, multi-ethnic population study from Oslo, Norway. International Journal of Behavioural Nutrition and Physical Activity, Vol.4, No.13, pp. 1-7, 2007. Doi:10.1186/1479- 5868-4-13.

[42] R.E. Evans, H.O. Fawole, S.A. Sheriff. Point-of-Choice Prompts to Reduce Sitting Time at Work a Randomized Trial. American journal of preventive medicine Vol. 43, No. 3, pp.293-97, 2012. Doi.org/10.1016/j.amepre.2012.05.010.

[43] J. Van Uffelen, J. Wong, H. Chau, I. Van der Ploeg, N. Riphagen, N. Gilson, G. Burton, A. Healy, B. Thorp, P. Clark, P. Gardiner, D. Dunstan, A. Bauman, N. Owen, W. Brown. Occupational Sitting and Health Risks: Systematic Review. American Journal of Preventive Medicine, Vol. 39 No. 4, pp.379-388, 2010. Doi: 10.1016/j.amepre.2010.05.02 4.

[44] A. Chu, S. Ng, C.S. Tan, A. M. Win, D. Koh, F. Muller-Riemenschneider. A systematic review and meta-analysis of workplace intervention strategies to reduce sedentary time in white collar workers. Obesity Reviews, Vol. 17, No. 5, pp. 467-81, 2016. Doi: 10.1111/obr.12388.

[45] A.M. Ezezue, E.O. Ibem, E.I. Kikanme, E.I. Safety Rest Areas and Fatigue Related Road Accidents in Enugu, Nigeria. International Journal of Innovative Technology and Exploring Engineering, Vol.8 No.8, pp. 1137-1144, 2019.

[46] National population Commission. Official gazette for the National Population and Housing Survey, Nigeria, Abuja, 2006.

[47] C.C. Nwachi, E.A. Agbor, S.A. Inah. A critical Evaluation of the Ogui Slum in Enugu, Nigeria. Global Journal of Social Sciences, Vo.11, No. 2, pp. 107-117, 2012. DOI: 10.4314/gjss.v11i2.3.

[48] W.G. Cochran. Sampling Technique. 2nd Edition, John Wiley and Sons Inc., New York, 1963.

[49] L. Frank, P. Engelke, T. Schmid. Health and community design: the impact of the built environment on physical 
activity. Island, Washington, 2003.

[50] Active by design: Designing places for healthy lives. A short guide, 2010. Retrieved June 30, 2020, from http://www.designcouncil.org.uk/sites/default/files/asset/do cument/Active_By_Design_Brochure_web_LATEST.pdf. 